\title{
AN IMPROVED OPTIMIZATION ALGORITHM FOR NETWORK SKELETON RECONFIGURATION AFTER POWER SYSTEM BLACKOUT
}

\author{
Haiping Liang
}

Original scientific paper Network skeleton reconfiguration is an important task during power system restoration after blackout. The uncertainty of the restoration time and the restoration successful rate during the network skeleton reconfiguration are considered in the paper. The restoration time of transmission lines and transformers, units' startup time limit and the restoration successful rate are selected as trapezoidal fuzzy variables. The optimal network skeleton reconfiguration model after power system blackout is constructed based on a fuzzy chance-constrained programming. An optimization algorithm combining fuzzy simulation with PSO is implemented to solve the optimal model. The optimal network skeleton with higher reliability and the restoration sequence which meet a certain confidence level are optimized by the proposed method. The restoration sequence can ensure the restoration as quickly as possible. The effectiveness of the proposed method is validated by Matlab with IEEE 30 bus system test.

Keywords: blackout; chance-constrained programming; network skeleton reconfiguration; particle swarm optimization; power system restoration

Poboljšani algoritam optimizacije za prerazmještaj sheme mreže nakon blokiranja energetskog sustava

Izvorni znanstveni članka

Prerazmještaj sheme mreže važan je zadatak tijekom restauracije energetskog sustava poslije blokiranja. U radu se razmatra nepredvidljivost vremena restauracije i uspješnosti brzine restauracije tijekom prerazmještaj sheme mreže. Vrijeme restauracije dalekovoda i transformatora, granično vrijeme pokretanja jedinica i brzina restauracije izabrani su kao trapezoidne fuzzy varijable. Optimalni model za prerazmještaj sheme mreže poslije blokiranja energetskog sustava izrađen je na osnovu fuzzy chance-constrained programiranja. Implementiran je algoritam optimizacije koji kombinira fuzzy simulaciju s PSO kako bi riješio optimalni model. Pouzdaniji optimalni skelet mreže i slijed optimizacije koji zadovoljavaju određeni nivo pouzdanosti optimiziraju se predloženom metodom. Slijed restauracije može osigurati što brže provođenje restauracije. Učinkovitost predložene metode provjerena je pomoću Matlaba s testom sustava sabirnice IEEE 30.

Ključne riječi: restauracija energetskog sustava; blokiranje; prerazmještaj sheme mreže; chance-constrained programiranje; optimizacija roja čestica

\section{Introduction}

Power system restoration after blackout is a complex decision and control problem. Many electric power companies have developed power system restoration schemes to simplify the operation and shorten the restoration procedure. Power system restoration involves the following three tasks: unit startup, network skeleton reconfiguration, and load pick-up. As far as network skeleton reconfiguration is concerned, its scheme has great effects on the whole restoration process, and it has been researched widely.

Reasonable network skeleton can reduce the burden of power system restoration effectively. The optimal network skeleton based on network reconfiguration efficiency and discrete particle-swarm optimization is researched in [1]. The network skeleton reconfiguration strategies based on assessment of node importance and line betweenness are proposed in $[2 \div 3]$. A network skeleton reconfiguration method using related node betweenness, topology priority and path electrical effects is proposed in [4]. But none of the above references involve in restoration sequence of transmission lines and transformers. A network reconfiguration algorithm considering both network skeleton optimization and restoration sequence optimization is studied in $[5 \div 6]$.

The restoration time of every transmission line and transformer is regarded as a certain factor in the former research, but the actual experience demonstrates that it is uncertain. The uncertain property of the restoration time is more suitable to be expressed as a fuzzy variable. Meanwhile, the restoration of transmission lines and transformers is not ideal. Considering the complex circumstance, the restoration maybe fails. Thus, the restoration successful rate is also uncertain and is suitable to be regarded as a fuzzy variable. It is necessary to consider the uncertainty of the restoration time and the restoration successful rate during the network skeleton reconfiguration, in order to make the network skeleton more reasonable.

The particle swarm optimization (PSO) is a computational method that optimizes a problem by iteratively trying to improve a candidate solution with regard to a given measure of quality. PSO is originally

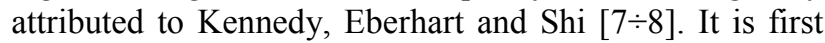
intended for simulating social behaviour in [9], as a stylized representation of the movement of organisms in a bird flock or fish school. The algorithm is simplified and it is observed to be performing optimization. An extensive survey of PSO applications is made in $[10 \div 11]$.

In this paper, regarding the restoration time and restoration successful rate as trapezoidal fuzzy variables, a network skeleton optimal configuration model based on the chance-contained programming (CCP) is constructed. According to the model characteristics, PSO is used to get the optimal network skeleton and the restoration sequence of the transmission lines and transformers.

\section{The optimal network skeleton reconfiguration model considering uncertainty}

A stable network skeleton of the power system should be rebuilt firstly, which is the goal of the power system restoration after blackout. And then the remaining unserved loads are restored. The objectives need to be achieved safely, flexibly, smoothly and deliberately in the 
shortest time. In order to fully consider the uncertainties the fuzzy chance-constrained programming combined optimization algorithm for network skeleton reconfiguration is proposed in the paper.

\subsection{Chance-constrained programming}

In a stochastic environment, in order to maximize the optimistic return with a given confidence level subject to some chance constraints [12], the following CCP model is provided as:

$$
\max _{x} \max _{f} \bar{f}
$$

subject to :

$$
\begin{aligned}
& \operatorname{Pos}\{f(\boldsymbol{x}, \boldsymbol{\xi}) \geq \bar{f}\} \geq \beta \\
& \operatorname{Pos}\left\{g_{j}(\boldsymbol{x}, \boldsymbol{\xi}) \geq 0, j=1,2, \ldots, p\right\} \geq \alpha
\end{aligned}
$$

where, $\boldsymbol{x}$ is a decision vector, $\boldsymbol{\xi}$ is a stochastic vector, $f(\boldsymbol{x}, \boldsymbol{\xi})$ is a return function, and $g_{j}(\boldsymbol{x}, \boldsymbol{\xi})$ are stochastic constraint functions, $j=1,2, \ldots, p . \alpha$ and $\beta$ are the given confidence levels, and $\bar{f}$ is the $\beta$-optimistic return. Pos $\{\cdot\}$ is the possibility measure.

\subsection{CCP based skeleton network reconfiguration model 2.2.1 Selection of fuzzy variables}

In the paper trapezoidal fuzzy variables are used to represent the restoration time for transmission lines and transformers. The trapezoidal fuzzy variable is shown in Fig. 1. A trapezoidal fuzzy variable means the fuzzy variable fully determined by quadruplet $\left(t_{1}, t_{2}, t_{3}, t_{4}\right)$ of crisp variables with $t_{1}<t_{2}<t_{3}<t_{4}, t_{1}$ is an optimistic restoration time, $t_{4}$ is a pessimistic restoration time, the time between $t_{2}$ and $t_{3}$ is the most likely restoration time.

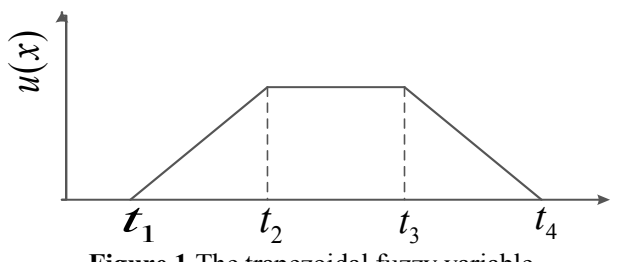

Figure 1 The trapezoidal fuzzy variable

Then membership function is given as the following.

$u(x)=\left\{\begin{array}{l}\frac{x-t_{1}}{t_{2}-t_{1}} \text { if } t_{1} \leq x \leq t_{2} \\ 1 \text { if } t_{2} \leq x \leq t_{3} \\ \frac{x-t_{4}}{t_{3}-t_{4}} \text { if } t_{3} \leq x \leq t_{4} \\ 0 \quad \text { otherwise }\end{array}\right.$.

\subsubsection{Reliability index of the skeleton network}

In the stage of network skeleton reconfiguration, assuming that power stations are completely reliable and then the restoration reliability will depend on the restoration successful rate of transmission lines and transformers. Assuming the restoration successful rate of the transmission lines and transformers is independent. If a restoration path includes several transmission lines and transformers, the reliability of the restoration path is defined as follows:

$$
R_{i}=\prod_{j=1}^{N_{i}} R_{i j}
$$

where $R_{i}$ is the reliability of the restoration path $i, R_{i j}$ is the restoration successful rate of the transmission line or transformer $j$ in restoration path $i, N_{i}$ is the number of transmission lines and transformers in the restoration path i.

Define the reliability of network skeleton is all the reliability of restoration paths, which is determined by the restoration successful rate of the transmission lines and transformers. The restoration reliability of the skeleton network is shown in Eq. (4).

$$
R=\frac{\sum_{i=1}^{N} R_{i}}{N}=\frac{\sum_{i=1}^{N} \prod_{j=1}^{N_{i}} R_{i j}}{N},
$$

where $R$ is the reliability of the skeleton network, $N$ is the number of the restoration path.

\subsubsection{The CCP model}

Considering the power system dispatching rules constraint, the units can only be allowed to be restored one by one. If there are more than one thermal unit, rational units' start-up sequence and loads restoration sequence might shorten the restoration time.

The objective function is as follows:

$$
\max _{R} \max _{f} \bar{f}
$$

Subject to:

$$
\begin{aligned}
& \operatorname{Pos}\left\{\frac{R}{T} \geq \bar{f}\right\} \geq \beta, \\
& \operatorname{Pos}\left\{T_{g} \geq \sum_{k=1}^{N_{G}} t_{g k}\right\} \geq \alpha, \\
& T=\sum_{m=1}^{N_{S}} t_{m},
\end{aligned}
$$

where, Eq. (5) is the objective function, it ensures the shortest restoration time and the highest reliability of network skeleton, the greater the better. Eq. (6) ensures the objective function value $\bar{f}$ at least at confidence level $\beta$. Eq. (7) ensures units can start-up at least at confidence level $\alpha, T_{g}$ is the critical maximum interval of unit $g$ $[13 \div 14], t_{g k}$ is the fuzzy restoration time of transmission line or transformer $k$ in restoration path $g$ which provides power supply to unit $g$, and it is a trapezoidal fuzzy 
variable, $N_{G}$ is the number of units needed to be restored. In Eq. (8), $T$ represents the total restoration time of the network skeleton, $t_{m}$ is the restoration time of the transmission line or transformer $m$, which is a trapezoidal fuzzy variable, $N_{S}$ is the number of transmission lines or transformers in the skeleton network.

In order to meet branches power and nodes voltage limits, power flow must be calculated. The network skeleton should obey the following constraints:

$$
\begin{aligned}
& P_{i}=U_{i} \sum_{j=1}^{N_{N}} U_{j}\left(G_{i j} \cos \delta_{i j}+B_{i j} \sin \delta_{i j}\right), \\
& Q_{i}=U_{i} \sum_{j=1}^{N_{N}} U_{j}\left(G_{i j} \cos \delta_{i j}-B_{i j} \sin \delta_{i j}\right), \\
& P_{g}^{\min } \leq P_{g} \leq P_{g}^{\max } \quad g \in N_{G}, \\
& Q_{g}^{\min } \leq Q_{g} \leq Q_{g}^{\max } \quad g \in N_{G}, \\
& U_{i}^{\min } \leq U_{i} \leq U_{i}^{\max } \quad i \in N_{V},
\end{aligned}
$$

(13)

$$
P_{l m} \leq P_{l m}^{\max } \quad m \in N_{S}
$$

where, Eq. (9) and Eq. (10) are the power balance equations. Eq. (11) and Eq. (12) are the inequality constraints of units. Eq. (13) is the inequality of buses voltage. Eq. (14) is the active power flow constraint in the transmission lines and transformers.

\section{The optimization solving algorithm of the network skeleton reconfiguration model}

In the paper, fuzzy simulation is used to check the fuzzy constraints and compute the fuzzy objective function. According to destination nodes and the power grid characteristics, the particle swarm optimization algorithm combined with fuzzy simulation and Floyd algorithm is used to get the restoration sequence of the nodes and the corresponding paths.

\subsection{The Floyd algorithm}

Floyd algorithm in the paper is used to find the shortest restoration paths of network. The Floyd algorithm compares all possible paths through the graph between each pair of vertices and can find the shortest path between every pair of vertices of a graph. As a result, a matrix $S$ denotes the shortest distance between vertices $i$ and $j$, and a matrix $P$ denotes the next vertex $k$ on the path from vertex $i$ to vertex $j$.

\subsection{Fuzzy simulation}

\subsubsection{The check of fuzzy constraints}

Fuzzy simulation is often used in fuzzy programming [15]. After the restoration paths which are from blackstart power source to the units to be restored were found through Floyd algorithm, the fuzzy constraints should be checked by fuzzy simulation. The fuzzy simulation steps are as follows.

Step 1: Generate crisp variables uniformly from fuzzy variables $t_{g k}, T_{g}$ at confidence level of $\alpha$.
Step 2: Check the constraints. If the crisp variables satisfy the chance constraints represented in Eq. (7), the restoration path is feasible.

Step 3: If the crisp variables are not satisfy the chance constraint represented in Eq. (7), generate the crisp variables again.

Step 4: If the chance constraints represented in Eq. (7) cannot be satisfied after $N$ times fuzzy simulation, the units cannot be restored using the current restoration sequence.

\subsubsection{Computation of the fuzzy objective function}

After checking the fuzzy constraints, the fuzzy objective function should be computed. The steps are shown as follows.

Step 1: Set $\bar{f}=-\infty$;

Step 2: Generate crisp variables uniformly from fuzzy variables $R_{i j}, t_{m}$ at confidence level $\beta$.

Step 3: Substitute the crisp variables into equations (4), (6) and (8). Calculate the objective function value $f$. If $\bar{f}<f$, then set $\bar{f}=f$.

Step 4: Go to step 2, repeat the fuzzy simulation for $N$ times. $\bar{f}$.

Step 5: Return the maximum objective function value

\subsection{The particle swarm optimization algorithm}

PSO is initialized with a group of random particles and then searches for optima by updating generations. In every iteration, each particle is updated by the following two best values. The first one is the local best fitness called pbest. Another best value is a global best called gbest. The algorithm has the following procedure:

Step 1: Random generation of an initial particle population.

Step 2: Reckon the fitness value, it will directly depend on the distance to the optimum.

Step 3: Modify gbest, pbest and particle velocity.

Step 4: Move each particle to a new position.

Step 5: Go to step 2, and repeat until convergence or a stopping condition is satisfied.

In the paper, PSO is used to calculate the optimal restoration sequence of the units and loads to be restored.

\subsection{The principle of the optimization solving algorithm}

The flowchart of the network skeleton reconfiguration algorithm principle is shown in Fig. 2.

The steps are shown as follows:

(1) Start and set the black-start power source, the units and loads to be restored.

(2) Calculate the shortest paths by Floyd algorithm, store the shortest distance between vertices with matrix $S$, store the next vertex on the path with matrix $P$. From matrix $S$ and matrix $P$ we can get the shortest path between any pair of vertices.

(3) Regarding the restoration sequence of units and loads to be restored as particles and initially the particle with random sequence. 
(4) Select the $i^{\text {th }}$ particle and search matrices $S$ and $P$ to get the restoration paths from black-start power source and the units or loads to be restored.

(5) Check the chance constraints through fuzzy simulation.

(6) If the chance constraints cannot be satisfied, then update the particles by mutation.

(7) If the chance constraints can be satisfied, then calculate the power flow and check whether the limits of nodes voltage and branches power can be satisfied.

(8) If the iteration times have reached $N_{p}$, then calculate the fitness.

(9) Updating the particles by cross.

(10) If the iteration times do not reach $N_{\max }$, then repeat again, otherwise output the optimal particles that mean the optimal restoration sequence.

(11) According to the optimal restoration sequence, the network skeleton can be gotten.

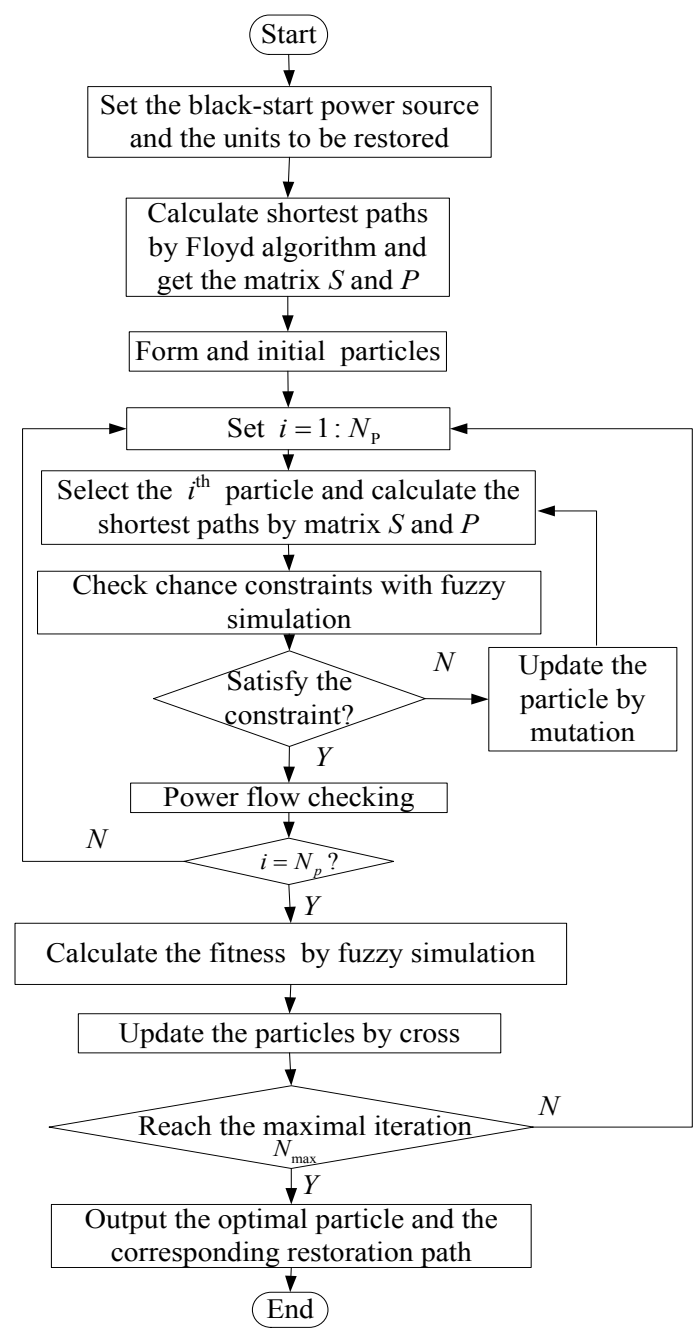

Figure 2 The flowchart of the network skeleton reconfiguration algorithm principle

\section{Application example and analysis}

The optimization solving algorithm proposed in the paper is implemented by Matlab and tested with IEEE30 bus system. In this system, there are 6 units and 40 transmission lines and transformers. Suppose the unit at bus 1 is the black-start unit, the units to be restored at bus [ [ $\left.\begin{array}{lllll}2 & 13 & 22 & 23 & 27\end{array}\right]$ and the load to be restored at bus [ [ $\begin{array}{lll}6 & 10 & 12\end{array}$
$15192130]$. Suppose the trapezoidal fuzzy restoration time of unit at bus 27 is $(10,12,18,20)$ minutes, the other units' trapezoidal fuzzy restoration time is $(20,25,30,35)$ minutes. The trapezoidal fuzzy restoration time of transmission lines is $(2 ; 2,2 ; 2,8 ; 3)$ minutes. The restoration successful rates of transmission lines are shown in Tab. 1.

During the network skeleton reconfiguration based on CCP, the number of particles is $N_{p}=10$, the maximal iteration $N_{\max }=100$, the times of fuzzy simulation $N=$ 1000 , the confidence level $\alpha=0,96, \beta=0,96$. During the power flow checking the maximal active power output of units to be restored is $30 \%$.

Table1 The restoration successful rates of transmission lines

\begin{tabular}{|c|c|}
\hline The transmission line & The restoration successful rate \\
\hline $3-4$ & $(0,9 ; 0,92 ; 0,98 ; 1)$ \\
\hline $4-6$ & $(0,9 ; 0,92 ; 0,98 ; 1)$ \\
\hline $8-28$ & $(0,9 ; 0,92 ; 0,98 ; 1)$ \\
\hline $10-20$ & $(0,9 ; 0,92 ; 0,98 ; 1)$ \\
\hline $10-17$ & $(0,9 ; 0,92 ; 0,98 ; 1)$ \\
\hline $22-24$ & $(0,9 ; 0,92 ; 0,98 ; 1)$ \\
\hline Others & $(0,85 ; 0,9 ; 0,95 ; 1)$ \\
\hline
\end{tabular}

After calculation by the proposed algorithm, the optimal network skeleton is shown in Fig. 3, in which the solid line shows the optimal network skeleton. Tab. 2 shows the restoration sequence and the corresponding restoration paths.

Table 2 The restoration sequence and the restoration path

\begin{tabular}{|c|c|c|}
\hline Sequence & $\begin{array}{c}\text { Bus to be } \\
\text { restored }\end{array}$ & $\begin{array}{c}\text { Transmission lines to be } \\
\text { restored }\end{array}$ \\
\hline 1 & 2 & $1-2$ \\
\hline 2 & 6 & $2-6$ \\
\hline 3 & 27 & $6-28,28-27$ \\
\hline 4 & 10 & $6-10$ \\
\hline 5 & 22 & $10-22$ \\
\hline 6 & 23 & $22-24,24-23$ \\
\hline 7 & 12 & $6-4,4-12$ \\
\hline 8 & 13 & $12-13$ \\
\hline 9 & 19 & $10-20,20-19$ \\
\hline 10 & 30 & $27-30$ \\
\hline 11 & 15 & $12-15$ \\
\hline 12 & 21 & $10-21$ \\
\hline
\end{tabular}

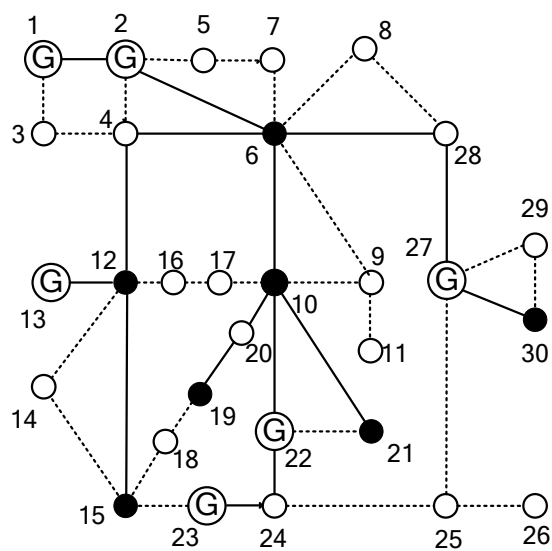

Figure 3 The network skeleton of IEEE 30 bus system

After calculation, the objective function value is 0,0204 , and the reliability of the skeleton network is 0,908 . The total restoration time of the network skeleton 
is 44,8 minutes. During the time all the units and the loads can be restored successfully.

As shown in Tab. 2 and Fig. 3, the network skeleton includes part of the transmission lines, which are 4-6, 1020 and 22-24 with high restoration successful rate. Although the transmission lines 3-4, 10-17 and 8-28 are also with high reliability, they do not need to be restored for their adjacency.

The results above have verified the effectiveness and correctness of the proposed method.

\section{Conclusion}

An improved optimization algorithm for the skeleton network reconfiguration after blackout is put forward in the paper. The restoration time of transmission lines and transformers, units' start-up time limit and the restoration successful rate are selected as trapezoidal fuzzy variables. The network skeleton optimal model is constructed based on CCP. An optimization algorithm combining fuzzy simulation with PSO is implemented to solve the network skeleton reconfiguration optimal model. The network skeleton and restoration sequence meet a certain confidence level. With the network skeleton having higher restoration reliability, the start-up power to units is provided as much as possible. The network skeleton and units restoration sequence are obtained and optimized by the proposed method. The effectiveness of the proposed method is validated by Matlab with IEEE 30 bus system test.

\section{Acknowledgements}

This paper is supported by "the Fundamental Research Funds for the Central Universities (13MS72)".

\section{References}

[1] Liu, Y.; Gu, X. P. Reconfiguration of Network Skeleton based on Discrete Particle-Swarm Optimization for BlackStart Restoration. // IEEE Power Engineering Society General Meeting / Montreal, 2006, pp. 1-7.

[2] Liu, Y.; Gu, X. P. Node Importance Assessment based Skeleton Network Reconfiguration. // Proceedings of the CSEE. 27, 10(2007), pp. 20-27.

[3] Wang, L.; Liu, Y.; Gu, X. P. Skeleton-Network Reconfiguration based on Node Importance and Line Betweenness. // Automation of Electric Power Systems. 34, 12(2010), pp. 29-33.

[4] Zhang, G. S.; Liu, J. Y.; Wei, Z. B. Skeleton-Network Reconfiguration based on Topology Priority and Path Electrical Effects. // Power System Protection and Control. 39, 17(2011), pp. 1-6.

[5] Lin, Z. Z.; Wen, F. S. A New Optimization Method for Determining Restoration Paths based on Weighted Complex Network Model. // Automation of Electric Power Systems. 33, 6(2009), pp. 11-15.

[6] Zhang, C.; Lin, Z. Z.; Wen, F. S. A Two Stage Strategy for Network Reconfiguration based on Concept of Regret. // Automation of Electric Power Systems. 37, 8(2013), pp. 46-52, 75 .

[7] Kennedy, J.; Eberhart, R. Particle Swarm Optimization. // Proceedings of IEEE International Conference on Neural Networks IV /Perth, 1995, pp. 1942-1948. DOI: 10.1109/ICNN.1995.488968
[8] Shi, Y.; Eberhart, R. C. A Modified Particle Swarm Pptimizer. // Proceedings of IEEE International Conference on Evolutionary Computation /Florida, 1998, pp. 69-73.

[9] Kennedy, J. The particle swarm: social adaptation of knowledge. // Proceedings of IEEE International Conference on Evolutionary Computation / Indianapolis, 1997, pp. 303-308. DOI: 10.1109/icec.1997.592326

[10] Poli, R. An Analysis of Publications on Particle Swarm Optimization Applications. // Technical Report CSM-469, 2007.

[11] Poli, R. Analysis of the publications on the applications of particle swarm optimization. // Journal of Artificial Evolution and Applications, (2008), pp. 1-10.

[12] Liu, B. D. Theory and Practice of Uncertain Programming. Springer-Verlag Berlin and Heidelberg GmbH, Physicaverl, 2009. DOI: 10.1007/978-3-540-89484-1

[13] Adibi, M. M.; Fink, L. H. Special Consideration in Power System Restoration. // IEEE Transaction on Power System. 12, 11(1992), pp. 1419-1427. DOI: 10.1109/mper.1992.161433

[14] Liu, C. C.; Liou, K. L.; Chu, R. F. Generation Capability Dispatch for Power System Restoration: A KnowledgeBased Approach. // IEEE Transaction on Power Systems. 8, 1(1993), pp. 316-325. DOI: 10.1109/59.221225

[15] Eberhart, R.; Kennedy, J. A New Optimizer Using Particles Swarm Theory. // Proceedings of the 6th International Symposium on Micro Machine and Human Science / Nagoya, 1995, pp. 39-43. DOI: 10.1109/MHS.1995.494215

\section{Author's addresses}

Haiping Liang, Lecturer

School of Electrical and Electronic Engineering

North China Electric Power University,

Baoding 071003, China

E-mail: lianghaiping@aliyun.com 